\title{
PENGUJIAN KERENTANAN SISTEM DENGAN MENGGUNAKAN METODE PENETRATION TESTING DI UNIVERSITAS XYZ
}

\author{
Jusia Amanda Ginting ${ }^{1}$, I Gusti Ngurah Suryantara ${ }^{2}$ \\ 1,2 Teknik Informatika \\ 1,2 Universitas Bunda Mulia, Jakarta, Indonesia \\ Correspondence email: jginting@ bundamulia.ac.id
}

Article history: $\quad$ Submission date: Juni 14,2021 Revised date: Juni 27, $2021 \quad$ Accepted date: Juni 30, 2021

\begin{abstract}
Awareness of information security will be a priority in the event of data loss or damage. This certainly harms the performance of a company or organization due to unpreparedness to resolve or minimize risks that can occur. The impact that occurs on the security system used is that the system cannot provide a sense of security because the system used and has security holes that can be used to exploit systems and networks at XYZ University. This study aims to examine the internal and external security controls of the system by identifying threats that can pose serious problems to assets at XYZ University by using the penetration testing method, the results can be used as a benchmark in measuring the weaknesses of the network and system from external attacks. The goal is to implement preventive controls against risks that can occur to improve system security at XYZ University.
\end{abstract}

Keywords: Vulnerability Testing, Penetration Testing, Preventive Control, Network Security

\begin{abstract}
ABSTRAK
Kesadaran akan keamanan informasi akan menjadi prioritas jika terjadi kehilangan atau kerusakan data. Hal ini tentu berdampak negatif terhadap kinerja sebuah perusahaan atau organisasi dikarenakan ketidaksiapan untuk menyelesaikan atau meminimalkan resiko yang bisa terjadi. Dampak yang terjadi pada sistem keamanan yang digunakan adalah sistem tidak bisa memberikan rasa aman dikarenakan sistem yang digunakan dan mempunyai celah keamanan yang dapat digunakan untuk mengeksploitasi sistem dan jaringan pada Universitas XYZ. Penelitian ini bertujuan untuk mengkaji kontrol keamanan internal dan eksternal sistem dengan mengidentifikasi ancaman yang dapat menimbulkan masalah serius terhadap aset pada Universitas XYZ dengan menggunakan metode penetration testing yang hasilnya dapat digunakan sebagai tolak ukur dalam mengukur kelemahan dari jaringan dan sistem dari serangan-serangan pihak luar dengan tujuan untuk mengimplementasikan pengendalian preventif terhadap resiko yang bisa terjadi untuk meningkatkan keamanan sistem pada Universitas XYZ.
\end{abstract}

Kata Kunci: Vulnerability Testing, Penetration Testing, Pengendalian Preventif, Network Security

\section{PENDAHULUAN}

Perkembangan teknologi informasi di era global saat ini turut mendorong perkembangan dari keamanan jaringan. Keamanan jaringan menjadi sangat penting untuk diperhatikan dikarenakan jaringan yang terhubung dengan perangkat lain atau dengan internet pada dasarnya tidak aman dan dapat dieksploitasi oleh para penyerang baik melalui jaringan LAN maupun Wireless (Hendrawan Manuaba et al, 2012).
Pada sebuah pengiriman data, data akan dikirimkan melewati beberapa terminal untuk sampai ke tujuan. Hal ini akan memberikan kesempatan pada user lain untuk menyadap atau mengubah data, bahkan mencuri data tersebut. Mengatasi hal ini, didalam perancangan dan pembangunan dari sebuah sistem keamanan jaringan harus direncanakan dan dipahami agar dapat melindungi sumber daya yang berada di dalam jaringan tersebut dan dapat meminimalisir terjadinya serangan. Selain melakukan pengamanan seperti melakukan update patch, penggunaan firewall, screening router, VPN, antivirus dan lain sebagainya, 
keamanan acapkali hanyalah sebagai ilusi yang difasilitasi dan dipercaya oleh orang-orang yang ada didalam sebuah organisasi (Ramadhani et al., 2010).

Menurut The European Union Agency For Network and Information Security (ENISA) permasalahan keamanan jaringan yang terjadi pada beberapa tahun terakhir adalah munculnya cryptoransomware yang bekerja dengan cara memanfaatkan vulnerability dari sebuah sistem operasi. Jenis kejahatan yang memanfaatkan vulnerability adalah pencurian identitas pribadi (Identity Thief) yang bertujuan untuk mencuri akun beserta password dan informasi-informasi penting lainnya. Kejahatan ini bisa dilakukan dengan menggunakan beberapa metode seperti phising, email scan atau dengan cara mendokumentasikan gerak-gerik user ketika mengakses situs di internet (Enisa, 2017).

GOV-CSIRT atau Government Computer Security Incident Response Team menjelaskan bahwa vulnerability assessment adalah tindakan identifikasi vulnerability dari suatu aplikasi, sistem operasi dan infrastruktur jaringan. Vulnerability assessment tidak melakukan eksploitasi celah atau kelemahan dari suatu sistem, Vulnerability assessment lebih fokus untuk menemukan beragam public vulnerability pada seluruh sistem komputer dalam jaringan target (Juardi, 2017). Penetration testing merupakan sebuah proses atau prosedur untuk mengevaluasi keamanan terhadap sistem komputer atau jaringan untuk menjalankan uji penetrasi yang terdiri dari 5 tahapan yaitu planning and reconnaissance, scanning, gaining access, maintaining access dan analysis (Lammle, 2005).

Pada penelitian sebelumnya yang dilakukan oleh Retna Mulya \& Tarigan pada tahun 2018 menghasilkan bahwa sistem jaringan komputer politeknik malang terdapat beberapa celah keamanan yang berstatus High Priority dengan menggunakan metode CVSS versi 3 dan FMEA (severity) untuk menentukan peringkat atau prioritas penanganan serangan berdasarkan dampak potensial yang ditimbulkan. Hasil penelitian menunjukkan tingkat kerentanan sistem jaringan komputer sebesar $40-60 \%$ (Retna Mulya \& Tarigan, 2018).

Penelitian yang dilakukan oleh Deris Stiawan, dkk pada tahun 2017 menyatakan bahwa penetration testing dapat digunakan sebagai alat untuk menemukan dan mengatasi kerentanan dalam infrastruktur jaringan yang menunjukkan seberapa rentan serangan pada sebuah jaringan. Mengatasi hal tersebut organisasi diharapkan dapat mengurangi kerentanan dari sistem dan jaringan sebanyak mungkin untuk meningkatkan keamanan jaringan (Stiawan et al., 2017).

Berdasarkan latar belakang yang sudah dijelaskan sebelumnya terdapat beberapa masalah yaitu: Sistem keamanan yang digunakan tidak bisa memberikan rasa aman dikarenakan sistem yang digunakan mempunyai celah keamanan yang dapat digunakan untuk mengeksploitasi sistem dan jaringan pada Universitas XYZ.

Adapun tujuan penelitian ini yaitu yang pertama melakukan vulnerability assessment dengan menggunakan tahapan penetration testing dan menggunakan metode sniffing, DoS, DDOS pada jaringan Universitas XYZ.

\section{METODE PENELITIAN}

Penelitian ini menggunakan arsitektur jaringan dan sistem pada Universitas XYZ di Jakarta sebagai objek penilaian vulnerability dengan menggunakan tahapan penetration testing:

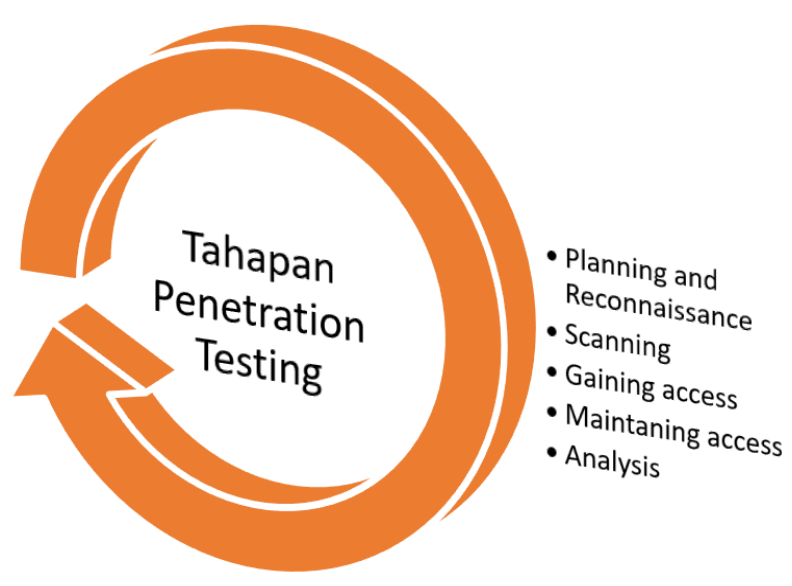

Sumber: (https://www.imperva.com)

Gambar 1. Tahapan Penetration Testing

Berdasarkan Gambar 1, tahapan penetration testing terdiri dari 5 tahapan yaitu pertama Planning and Reconnaissance yaitu menentukan ruang lingkup pengujian dan metode pengujian yang akan digunakan pada objek penelitian. Kedua Scanning atau memindai target menggunakan tools yang ada untuk mencari keamanan yang bisa digunakan untuk masuk kedalam sistem objek. Ketiga Gaining Access merupakan percobaan menerobos masuk dengan menggunakan teknik-teknik seperti sniffing, sql injection, Xss dengan tujuan mengeksploitasi sistem, mencuri data, memantau traffic jaringan, dan monitoring kegiatan user pada objek yang diteliti. Kelima Maintaining access, yaitu apakah akses yang sudah didapatkan pada proses sebelumnya dapat ditutup sehingga keamanan dari sistem tetap aman. Dan Kelima Analisis pembuatan laporan dari rangkaian kegiatan yang sudah dilakukan seperti celah keamanan, data yang diambil, dan waktu (Nugroho, 2001). 


\section{HASIL DAN PEMBAHASAN}

Proses dan tahapan yang digunakan dalam menguji vulnerability di Universitas XYZ menggunakan tahapan Penetration Testing. Berikut ini adalah tahapan yang dilakukan:

Tahap pertama Planning dan Reconnaissance dilakukan dengan metode wawancara dengan pihak administrator jaringan di Universitas XYZ dan observasi arsitektur jaringan yang dapat dilihat tanpa menggunakan bantuan tools yang terkait seperti pada Gambar 2.

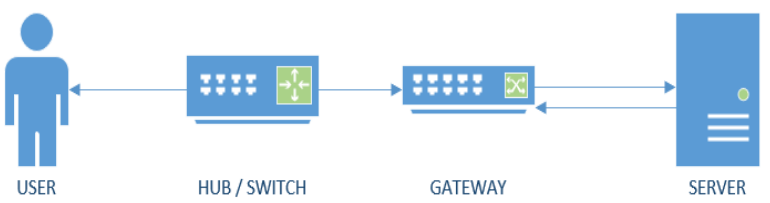

Sumber : (Jusia Amanda Ginting, 2021)

Gambar 2. Skema Jaringan Normal

Gambar 2 mengilustrasikan skema dari sebuah jaringan normal dimana seorang user dapat terhubung ke sebuah server melalui perangkat switch atau router tanpa adanya intervensi dari penyerang.

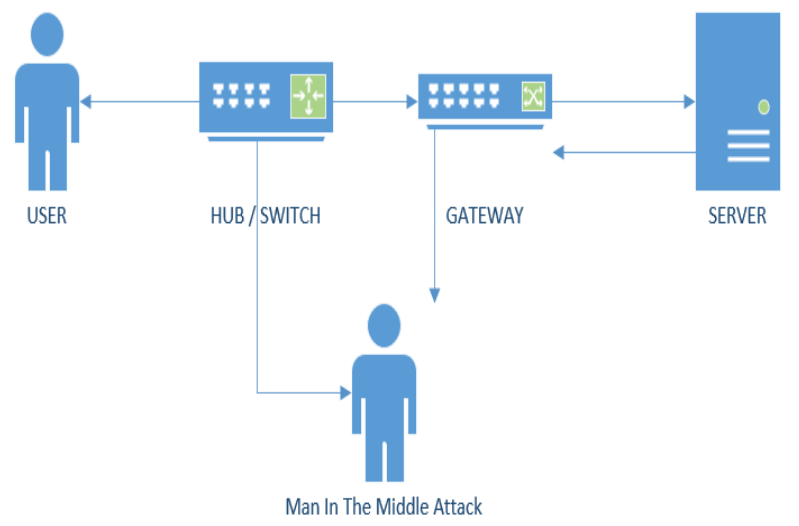

Sumber : (Jusia Amanda Ginting, 2021)

Gambar 3. Skema serangan Sniffing

Gambar 3 mengilustrasikan skema penyerangan terhadap jaringan normal dengan menggunakan konsep penyerangan Sniffing (Man in the middle Attack). Penyerang dapat mendapatkan semua informasi ketika terdapat user yang melakukan request ke server (M.-y. Su, K.-c. Chang, 2009).

Tahap kedua yaitu melakukan scanning pada jaringan yang digunakan untuk melihat service apa saja yang diberikan server ke client. Tools yang digunakan untuk melihat service pada server target adalah dengan menggunakan software port scanner NMAP.

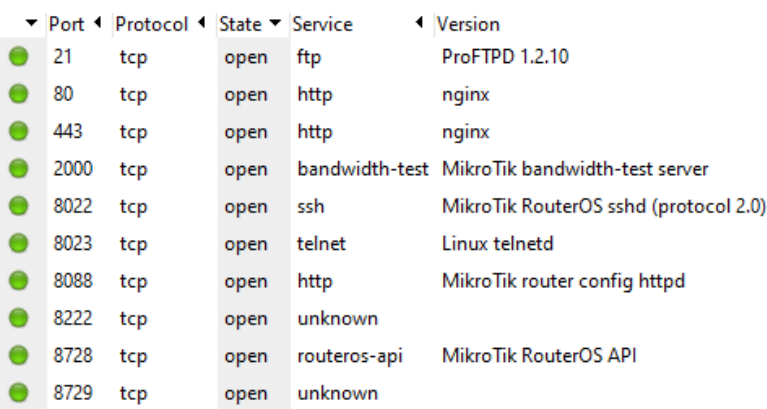

Sumber : (Jusia Amanda Ginting, 2021) Gambar 4. Port Scanning

Gambar 4. Merupakan hasil dari port scanning yang dilakukan pada Universitas XYZ yang menghasilkan informasi mengenai port yang sedang terbuka pada sistem. Seperti pada Gambar 4, target menggunakan port 8022 dengan menggunakan protokol TCP dan status dari port tersebut open, Hal ini tentu saja dapat dimanfaatkan oleh attacker untuk masuk kedalam sistem dengan menggunakan kombinasi password.

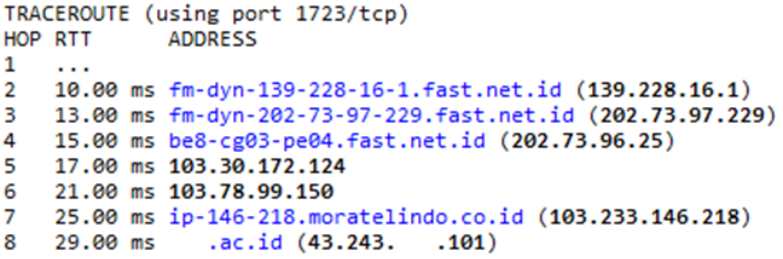

Sumber : (Jusia Amanda Ginting, 2021) Gambar 5. TraceRoute

Gambar 5 merupakan hasil dari traceroute yang sudah berhasil dilakukan dengan menggunakan tools NMAP. Traceroute dilakukan dengan tujuan untuk menentukan rute yang dilewati paket untuk mencapai tujuan dengan cara mengirimkan paket ICMP.

Tabel 1. Presentasi Sistem Operasi Universitas XYZ

\begin{tabular}{clc}
\hline No & \multicolumn{1}{c}{ OS } & Persentase \\
\hline 1 & $\begin{array}{l}\text { HP P2000 G3 NAS } \\
\text { DEVICE }\end{array}$ & $91 \%$ \\
2 & LINUX & $90 \%$ \\
3 & $\begin{array}{l}\text { AXIS 201A } \\
\text { (Network Camera) }\end{array}$ & $90 \%$ \\
4 & $\begin{array}{l}\text { Asus RT-AC66u } \\
\text { Router }\end{array}$ & $89 \%$ \\
5 & Asus RT-N16 & $89 \%$ \\
6 & FreeBSD & $90 \%$ \\
\hline
\end{tabular}

Sumber : (Jusia Amanda Ginting, 2021) 
Selain mendapatkan informasi rute pengiriman paket, NMAP dapat menampilkan presentasi sistem operasi yang digunakan pada sistem tersebut. Bagi user pada umumnya informasi yang ditampilkan pada Tabel 1, bukan merupakan sebuah informasi yang berharga, tetapi berbeda dengan attacker, informasi ini akan dimanfaatkan untuk mendapatkan kelemahan dari sistem operasi yang digunakan pada Universitas XYZ (Tejay, 2009).

Tahap ketiga yaitu Gaining Access. Tahapan ini dilakukan paket sniffing dan ARP Spoofing Poisoning yang gunakan untuk meng capture seluruh traffic masuk dan keluar dari jaringan tersebut termasuk password dan username yang digunakan oleh user dengan cara memodifikasi traffic dan menghentikan traffic. Tools yang digunakan untuk melakukan serangan ini adalah Cain and Abel (Fauzi \& Suartana, 2018).

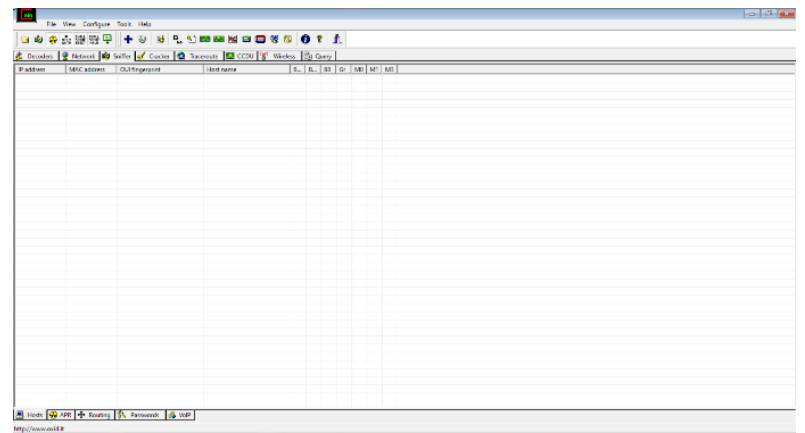

Sumber : (Jusia Amanda Ginting, 2021) Gambar 6. Tool Cain and Abel

Prinsip dari serangan ARP Poisoning ini adalah dengan cara memanfaatkan kelemahan pada teknologi jaringan komputer itu sendiri dengan menggunakan ARP Broadcast yang berada pada layer 2 (MAC Address) (Beghdad, 2009).

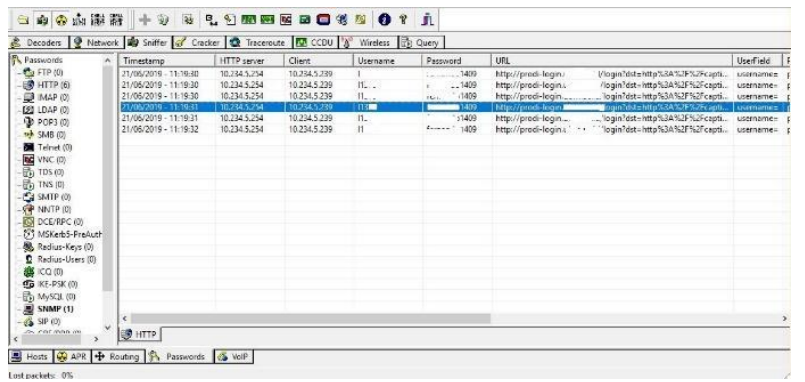

Sumber : (Jusia Amanda Ginting, 2021) Gambar 7. Sniffing Universitas XYZ

Gambar 7 menampilkan hasil sniffing yang sudah dilakukan pada Universitas XYZ. Dari penyerangan yang dilakukan dapat dilihat bahwa jaringan pada Universitas XYZ memiliki kelehaman seperti tidak menggunakan enkripsi pada username dan password.
Tabel 2. Username dan Password

\begin{tabular}{lll}
\hline \multicolumn{1}{c}{ User } & $\begin{array}{l}\text { Passwo } \\
\text { rd }\end{array}$ & \multicolumn{1}{c}{ URL } \\
\hline L17xx & A13xx & Lecxxx.ubx.co.i \\
& xxxx & d \\
1801xxxx & solxxxx & App.bunxxxx.ac \\
& xxx & .id/budget \\
1801xxxx & ardxxx & App.bunxxxx.ac \\
& xxxx & .id/budget \\
L12xx & Yoxxx & Lecxxx.ubx.co.i \\
& xx & d \\
L16xx & jooxxx & Lecxxx.ubx.co.i \\
& xx & d \\
L01xx & naxxxx & Lecxxx.ubx.co.i \\
& xx & $\mathrm{d}$ \\
L07xx & Luxxxx & Lecxxx.ubx.co.i \\
& xxxx & d \\
L16xx & $90 x x x x$ & Lecxxx.ubx.co.i \\
& xx & d \\
L14xx & Zaxxxx & Lecxxx.ubx.co.i \\
& xx & d \\
Phandxxxx@bundx & sayxxx & Mail.bunxxxx.a \\
xxxxx.ac.id & xx & c.id \\
\hline \multicolumn{2}{c}{ Sumber : (Jusia } & Amanda Ginting, 2021)
\end{tabular}

Tahap berikutnya adalah Maintaining Access dari hasil sniffing yang sudah dilakukan seperti pada Gambar 8.

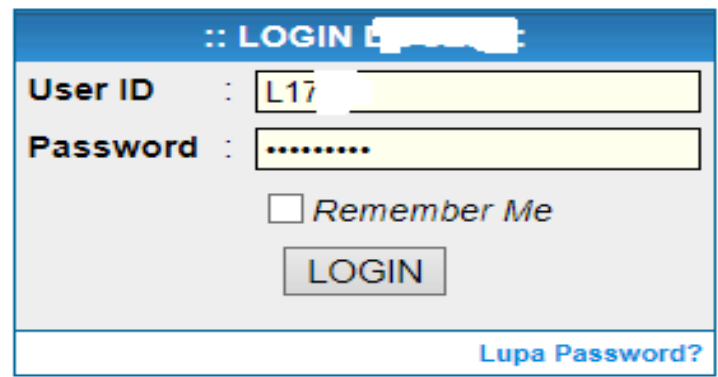

Sumber : (Jusia Amanda Ginting, 2021)

Gambar 8. Login situs Lecxxx.xxx.co.id

Username dan Password yang digunakan ketika melakukan Login adalah Username dan Password yang sudah didapatkan pada proses sniffing.

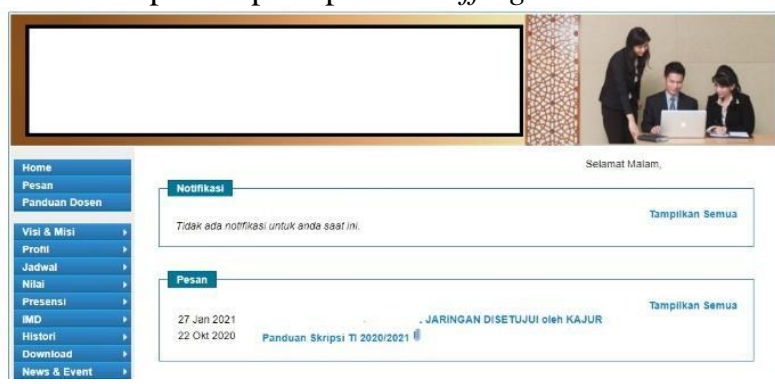

Sumber : (Jusia Amanda Ginting, 2021)

Gambar 9. Situs Lecxxx.xxx.co.id 
Setelah melakukan sniffing maka dilakukan stress testing untuk menguji kehandalan dari server didalam jaringan Universitas XYZ, dengan menggunakan serangan DDoS yang akan membanjiri jaringan atau server dengan traffic data yang berlebihan dengan tujuan untuk membuat kinerja sistem menurun dalam menangani traffic data yang berlebih.

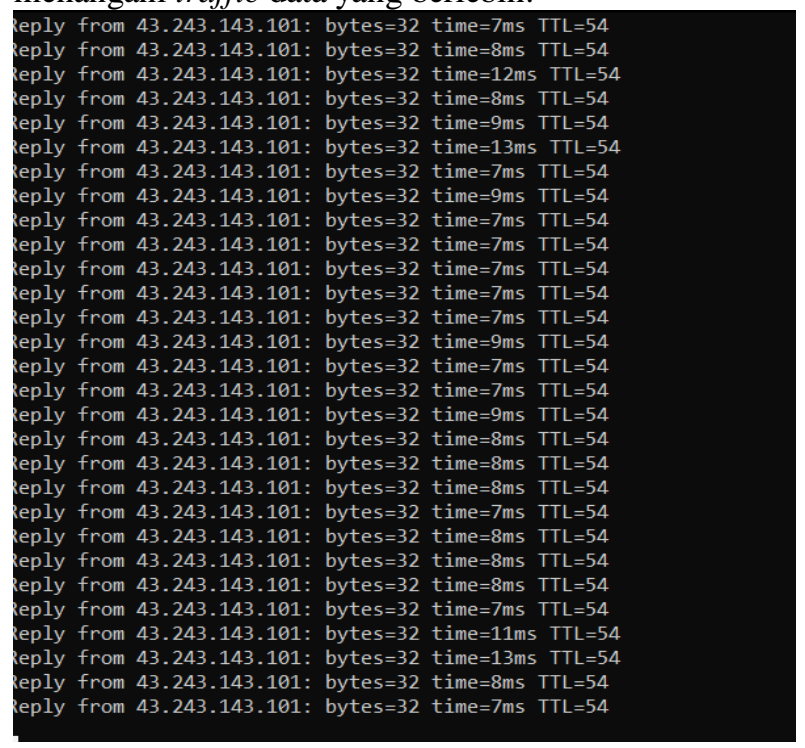

Sumber : (Jusia Amanda Ginting, 2021) Gambar 10. TTL Sebelum Penyerangan

Gambar 10 menunjukkan kondisi dari situs Lecxxx.xxx.co.id sebelum dilakukan penyerangan. Dari hasil ping yang dilakukan kategori throughput (100), delay $(<150 \mathrm{~ms})$ dengan jitter 0 . Setelah melakukan pengamatan jaringan sebelum penyerangan DDoS, langkah selanjutnya adalah melakukan pengujian stress testing dengan menggunakan tools HOIC.

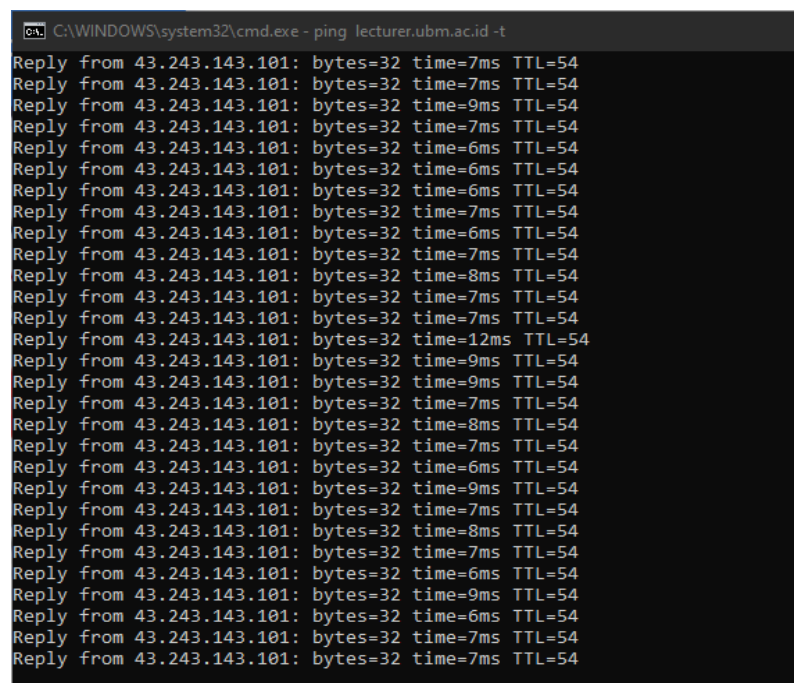

Sumber : (Jusia Amanda Ginting, 2021)

Gambar 11. Hasil Stress Testing (DDoS)
Hasil stress testing dengan menggunakan tools HOIC pada situs http://lecxxxxx.ubx.ac.id tidak mengalami kendala dan masih dapat melayani setiap request yang dikirimkan oleh user.

\section{KESIMPULAN}

Adapun kesimpulan yang didapatkan selama melakukan penelitian ini adalah Software Cain and Abel mampu untuk membaca dan meng capture seluruh lalu lintas jaringan kabel maupun nirkabel yang ada pada Universitas XYZ. Hal ini tentu saja dapat menjadi perhatian dari pihak Universitas untuk mengamankan jaringan dan port yang terbuka pada jaringan di Universitas tersebut. Penggunaan enkripsi pada aplikasiaplikasi pada Universitas XYZ sangat diperlukan dikarenakan jenis password yang didapatkan masih berupa plaintext. Pengujian stress testing pada Universitas XYZ yang dilakukan dengan menggunakan serangan DDoS tidak menimbulkan dampak yang signifikan terhadap situs Universitas XYZ.

\section{DAFTAR PUSTAKA}

Beghdad, R. (2009). ritical study of neural networks in detecting intrusions. Computers \& Security, 5, $168-175$.

Enisa. (2017). Cyber Security Culture in Organisations. European Union Agency for Network and Information Security. Athens.

Fauzi, A., \& Suartana, I. (2018). Monitoring Jaringan Wireless Terhadap Serangan Packet Sniffing Dengan Menggunakan Ids. Jurnal Manajemen Informatika, 8(2).

Ida Bagus Verry Hendrawan Manuaba, Risanuri Hidayat, S. S. K. (2012). Evaluasi Keamanan Akses Jaringan Komputer Nirkabel ( Kasus: Kantor Pusat Fakultas Teknik Universitas. Jnteti, I(1), 5 .

Juardi, D. (2017). Kajian Vulnerability Keamanan Jaringan Internet Menggunakan Nessus. Syntax Jurnal Informatika, 6(1), 11-19. https://journal.unsika.ac.id/index.php/syntax/articl e/view/1148/Kajian Vulnerability Keamanan Jaringan Internet Menggunakan Ness

Jusia Amanda Ginting, I. G. N. S. (2021). Pengujian kerentanan sistem dengan menggunakan metode Penetration testing di universitas xyz.

Lammle, T. (2005). Cisco Certified Network Associate Study Guide. Elex Media Komputindo.

M.-y. Su, K.-c. Chang, and C. -y. L. (2009). Attack Patterns Discovery by Frequent Episodes Mining from Honeypot Systems. 301-306. 
Nugroho, M. A. (2001). Studi Kasus Celah Keamanan Pada Jaringan Nirkabel Yang Menerapkan Wep (Wired Equivalent Privacy).

Ramadhani, Erika, A. A. (2010). Analisa Keamanan Jaringan Nirkabel di Universitas Gadjah Mada Dengan Menggunakan Metode Wardriving. Magister Teknologi Informasi Universitas Gadjah Mada.

Retna Mulya, B. W., \& Tarigan, A. (2018). Pemeringkatan Risiko Keamanan Sistem Jaringan Komputer Politeknik Kota Malang Menggunakan Cvss Dan Fmea. ILKOM Jurnal Ilmiah, 10(2), 190-200. https://doi.org/10.33096/ilkom.v10i2.31 $1.190-200$
Stiawan, D., Idris, M. Y., Abdullah, A. H., Aljaber, F., \& Budiarto, R. (2017). Cyber-attack penetration test and vulnerability analysis. International Journal of Online Engineering, 13(1), 125-132. https://doi.org/10.3991/ijoe.v13i01.6407

Tejay, G. D. and G. (2009). Developing Insider Attack Detection Model: A Grounded Approach. 107112. 